\title{
IDENTIDADES, AFETIVIDADES E PRÁTICAS PEDAGÓGICAS DE PROFESSORAS DE GEOGRAFIA NO ENSINO DA CIDADE DE FEIRA DE SANTANA/BA E A INFLUÊNCIA NA FORMAÇÃO DO SIGNIFICADO DESTE LUGAR POR ALUNOS DE UMA ESCOLA PÚBLICA ${ }^{1}$
}

\section{Identidades, afectividades y prácticas pedagógicas de profesoras de geografía en el enseño de la ciudad Feira de Santana/BA y la influencia en la formación del significado de este lugar por alumnos de una escuela pública}

\author{
Estudante do curso de Geografia da Universidade Estadual de Feira de Santana - BA \\ edsonsporte@hotmail.com
}

Célia Regina Batista dos Santos

Professora Titular da Universidade Estadual de Feira de Santana - BA celia_regina2006@hotmail.com

Artigo recebido em 15/08/2016 e aceito para publicação em 18/11/2016

DOI: 10.12957/tamoios.2016.25119

"E nas mensagens que nos chegam sem parar, ninguém pode notar. Estão muito ocupados pra pensar”. Raul Seixas

\section{Resumo}

O estudo do lugar no atual contexto histórico, tem se destacado por se constituir um excelente laboratório para se compreender o mundo, possibilitando analisar fenômenos que acontecem a nível global e se manifestam em locais específicos, concretos, a exemplo da cidade de Feira de Santana, na Bahia. Dito isso, o presente trabalho traz os resultados de um estudo de caso que teve por objetivo analisar as identidades, afetividades e práticas pedagógicas de professoras de geografia em relação à cidade de Feira de Santana, bem como a influência da sua mediação pedagógica na formação e/ou reafirmação de identidades e imagens dos alunos em relação a este lugar. A produção dos dados ocorreu entre os meses de julho a agosto de 2014 num colégio Estadual de Feira de Santana/BA, e contou com a aplicação de questionários e realização de entrevistas semiestruturadas junto a 32 alunos do ensino fundamental e médio e 05 professoras de geografia. Os principais resultados apontam que todos os sujeitos investigados possuem laços de identidade com o lugar Feira de Santana; as ideias e discursos das professoras influenciam nas imagens que os alunos elaboram sobre a referida cidade; suas práticas pedagógicas são norteadas por recursos didáticos elaborados em aula.

Palavras-chave: Lugar; Feira de Santana; Mediação Pedagógica.

\section{Resume}

El estudio de lugar, en el actual contexto histórico, tiene un contenido especial realce por ser constituido en un excelente laboratorio, para así comprender el mundo, haciendo posible analizar los fenómenos que ocurren a nivel mundial, y se manifiestan en lugares concretos, a ejemplo de la ciudad Feira de Santana. Dicho eso, el presente trabajo trae los resultados de un estudio de caso que tuve por objetivo, analizar las identidades, afectividades y prácticas pedagógicas de los profesores de geografía en relación de la ciudad de Feira de Santana, así como la influencia de su mediación pedagógica en la formación y/o reafirmación de identidades e imagines de los alumnos en relación a este lugar. La producción ocurrió entre los meses de julio a agosto de 2014, y contó con aplicación de cuestionarios y realización de entrevistas semiestructuradas junto a 32 alumnos del enseño Fundamental e Medio y 05 profesoras de geografía. Los principales resultados apuntan que todo los sujetos investigados tiene lazos identitários con el lugar Feira de Santana; la ideas y discursos de las profesoras influencian en la imagines que los alumnos elaboran sobre la referida ciudad; sus prácticas pedagógicas son norteadas por recursos didácticos elaborados en la propia clase.

Palabras clave: Lugar; Feira de Santana; Mediación Pedagógica. 


\section{Introducão}

Estudar o lugar na atual configuração sócio espacial se faz necessário, pois o meio técnico-cientifico-informacional, impulsionado pelo processo de globalização, tende a promover alterações que almejam homogeneizar gostos e costumes nas mais variadas escalas, desde a mundial até a local. Todavia, essas alterações são sentidas de forma mais contundente no lugar de vivência, uma vez que as transformações ocorrem a uma velocidade e intensidade tão desmedidas que causam estranheza nos sujeitos quando as percebem, ao ponto de não se sentirem pertencentes à realidade local.

Compreender essas transformações é importante, visto que vários estudos apontam ser nessa escala (a local) que os sujeitos vivenciam as contradições socioeconômicas, de forma mais contundente, ao desenvolverem suas práticas sócio espaciais cotidianas, as quais contribuem para a formação e/ou reafirmação de identidade(s). Desta forma, deve ser por ela que os sujeitos devem começar a desenvolver maneiras de se fortalecer para enfrentar as diversas situações.

$\mathrm{Na}$ busca de enfrentar esses desafios cotidianos ressaltamos a importância das instituições escolares, entendidas neste trabalho como responsáveis por contribuir para a formação de ideias e opiniões, para ampliar os conhecimentos dos alunos sobre o lugar onde moram. Nesse contexto, situamos no centro das discussões as contribuições da Geografia, fornecendo bases teóricas e metodológicas que subsidiam reflexões que contribuem para diagnosticar problemas e propor intervenções que contemplam as mais variadas escalas, inclusive o lugar de vivência. Para tanto, cabe à escola e ao professor de geografia desenvolver com os alunos um ensino significativo capaz de emancipá-los, fornecendo-lhes ferramentas que os possibilitem realizar leituras e análises críticas das contradições presentes no seu lugar de vivência, assim como relacioná-lo a outras escalas de análise.

A partir desses pressupostos essa investigação, dentro dos seus limites, traz uma reflexão sobre a influência da prática pedagógica e dos discursos dos professores de geografia na ampliação dos saberes e formação da (s) identidade (s) dos alunos com o lugar de vivência, que no caso em estudo se refere à cidade de Feira de Santana. Entendemos que a importância atribuída ao lugar, à afetividade e o sentimento de pertencimento possibilitam potencializar a relação dos sujeitos com o seu lugar de vivência, favorecendo a compreensão de seus problemas, limites e potencialidades, no sentido de buscar formas de intervir no mesmo.

Estruturalmente esse trabalho está organizado da seguinte forma: inicialmente é realizada uma reflexão sobre o estudo do lugar na educação básica e a importância da mediação pedagógica que considere o aluno como sujeito ativo no processo de ensinoaprendizagem. Posteriormente é apresentado o suporte metodológico, que consiste num estudo de caso, ancorado em bases da pesquisa qualitativa, desenvolvido com professoras e alunos da escola básica de um colégio público situado na periferia de Feira de Santana, segunda maior cidade do Estado da Bahia. Por fim, são apresentados os resultados, analisados em forma de narrativas, onde são pontuadas a influência do professor na formação e construção da identidade dos alunos para com o lugar Feira de Santana.

\section{O Estudo do Lugar nas aulas de Geografia e a mediacão pedagógica}

O presente estudo entende a cidade de Feira de Santana como a extensão territorial do lugar, compreendido nesta pesquisa como um fragmento do espaço geográfico dotado de significados, contido num todo, de onde mantêm relações através das mais variadas articulações com outras escalas. Por ser um fragmento, o lugar é entendido por Carlos (2007) como uma porção do espaço apropriável para a vida, passível de ser significado, refletido e 
apropriado através do corpo e dos sentidos, no momento em que as pessoas o exploram e vivenciam, a exemplo da cidade (e nela o bairro, a rua, a praça...). Para a referida autora, as relações tecidas socialmente ocorrem " [...] no plano do vivido, o que garante a constituição de uma rede de significados e sentidos que são tecidos pela história e cultura civilizatória que produz a identidade homem - lugar, que no plano do vivido vincula-se ao conhecido reconhecido" (CARLOS, 2007, p. 22).

Entendemos que estudar o lugar na escola, tomando o espaço de vivência dos alunos, tende a contribuir para a formação e/ou reafirmação das identidades dos educandos para com o seu lugar, pois parte-se do pressuposto de que quem conhece admira, quem admira gosta e quem gosta, luta pelo desenvolvimento social, econômico, cultural e político da cidade (bairro, rua, praça, distrito, povoado) onde vive (SANTOS, 2007). Ou seja, para além do estudo conceitual, estudar esse tema pressupõe o despertar da consciência crítica dos alunos para com o seu lugar e assim contribuir na formação de sujeitos atuantes. Para tanto, é importante que o estudo da escala local, bem como a problematização da mesma, seja realizado sempre articulando com as demais escalas geográficas. Ademais é imprevisível que tal estudo ocorra constantemente ao longo da escolarização e não apenas em uma unidade prevista nos livros didáticos do $6^{\circ}$ ano como comumente acontece.

Corroboramos com Callai (2000), de que a importância de estudar esse tema na escola consiste no fato de que, ao estudá-lo, podemos compreender a história do lugar onde vivemos, assim como nos fornecerá subsídios para que possamos entender as transformações e os rebatimentos que acontecem no lugar onde moramos, pois para a referida autora "[...] nenhum lugar é neutro, pelo contrário, é repleto de história e com pessoas historicamente situadas num tempo e num espaço, que pode ser o recorde de um espaço maior, mas por hipótese alguma é isolado, independente" (CALLAI, 2000, p. 84).

Também concordamos com Lima e Thomaz (2007) de que o estudo do lugar (realidade local) pode contribuir para que os alunos tenham maior interesse em participar das aulas, assim como das transformações que ocorrem em seu lugar, pois através deste estudo eles podem perceber que também são agentes transformadores do seu espaço, possibilitando assim uma maior participação na comunidade onde vivem. Os autores ressaltam que o fato de os alunos realizarem estudos distantes de sua realidade e, por conseguinte, longe de seu campo de poder e ação, não desperta o interesse em se mobilizarem na busca por resolução de possíveis problemas que estão ocorrendo no seu lugar.

Diante do exposto, é importante que o professor, ao assumir a função mediadora, facilite a aprendizagem tornando o conhecimento significativo e desejável para o aluno, bem como o entenda enquanto sujeito ativo durante o processo.

A mediação pedagógica envolve aspectos relacionados ao comportamento que o professor estabelece ao buscar facilitar, incentivar e motivar os alunos durante a aprendizagem, apresentando-se como uma ponte entre o aluno e sua aprendizagem. Não uma ponte estática, mas uma ponte "rolante" que ativamente colabora para que o aprendiz chegue aos seus objetivos e possa elaborar um conhecimento significativo que seja incorporado ao seu mundo intelectual e vivencial, que o ajude a ampliar a compreensão sobre a sua realidade humana e social, e mesmo a interferir nela (MASETTO, 2000).

Em se tratando do estudo do lugar, no processo de mediação pedagógica é importante que o aluno seja entendido como um sujeito ativo que elabora conhecimentos no seu dia-a-dia a partir de suas experiências com o espaço de vivência, devendo-se levar em consideração, durante a construção do conhecimento, a combinação das ideias (saberes, afetividades) presentes nas falas dos alunos, as quais são formuladas, adotadas e aplicadas no seu dia-a-dia, pois como adverte Cavalcanti (2000) os conceitos que a ciência geografia utiliza para realizar 
suas análises e discussões são os mesmos presentes no cotidiano das pessoas, porém, carregados de senso comum.

É igualmente importante que a mediação pedagógica leve em consideração as articulações existentes entre o local e o global, “[...], pois um está incluído no outro, de forma que ambos devem ter sua importância respeitada em parâmetros locais e globais, dentro de uma sociedade possuidora de características globalizadas e locais" (BENTO, 2011, p. 76). Essa articulação permite que os alunos percebam que, com o processo de globalização, fluxos e transformações estão articulados e se materializam em lugares específicos, pois na maioria das vezes as explicações podem estar fora, sendo necessário buscar aspectos tanto internos, quanto externos, para se realizar análises mais consistentes e dessa forma compreender o que acontece em cada lugar (CALLAI, 2000). Essa articulação é importante para que o ensino desse conteúdo possa superar a perspectiva teórico-metodológica que, hora caracteriza-se por apresentar o estudo do lugar como ponto de partida aumentando gradativamente as dimensões espaciais a serem estudadas; e hora apoia-se na abordagem analítica onde o processo é inverso, ou seja, inicia-se com o que é desconhecido e distante para depois seguir em direção ao lugar de convivência do estudante ${ }^{2}$.

Desta forma, estudar e perceber o lugar Feira de Santana requer compreendê-lo como historicamente construído e apropriado por pessoas no seu dia-a-dia, como 'espaço de vivência', resultado da história de vidas. Ao mesmo tempo em que ele é "[...] palco onde se sucedem os fenômenos, ele é também ator/autor, uma vez que oferece condições, põe limites, cria possibilidades" (CALLAI, 2005, p. 236). Para tanto, defendemos que na mediação pedagógica desse conteúdo (e de qualquer conteúdo da geografia ou demais disciplinas escolares), o professor deve estabelecer articulações com as múltiplas escalas geográficas, contanto que não sejam tomadas de forma hierárquica, no sentido de ter que seguir uma linearidade (partindo de uma grande escala para uma menor e vice-versa), muito menos como instâncias iniciais e isoladas.

Nessa perspectiva, o lugar Feira de Santana não deve ser entendido apenas como ponto de partida, mas sim na relação que se pode estabelecer entre ele e as demais escalas de análise. Partimos do pressuposto de que o estudo desse lugar nas escolas pode contribuir para que os alunos feirenses se percebam como agentes transformadores do seu espaço, despertando um maior interesse em participar das aulas, assim como das transformações que ocorrem nesta cidade, mobilizando-se na busca por resolução de possíveis problemas que estejam ocorrendo nesse lugar.

Diante do exposto consideramos relevante ressaltar que o processo de mediação pedagógica, na abordagem desse tema/problema, requer pensar nos saberes, afetividades, identidades dos professores em relação ao lugar de vivência que será abordado. Uma pesquisa realizada por Santos (2007), com professores de geografia de Feira de Santana, indicou que os mesmos não estudaram esse lugar durante a sua formação inicial e que os trabalhos de campo que geralmente faziam eram realizados em outras cidades da Bahia. De acordo com a pesquisa, quando abordavam o lugar Feira de Santana em suas aulas, os seus conhecimentos, geralmente, eram (são) provenientes do senso comum, de experiências espaciais na cidade, de jornais, revistas e outros materiais informativos.

Para a referida autora, ao se apoiar em conhecimentos superficiais e impressões pessoais sobre o lugar de vivência, é possível que, durante as aulas, os professores expressem uma linguagem não verbal, por meio de gestos, expressões e entonações da voz, que se encontra arraigada de discursos oriundos do senso comum, das suas experiências (boas ou ruins) no lugar de vivência/trabalho, de afetividades, de identidades (ou ausência delas). Em síntese, através de seu discurso e saberes, o professor pode contribuir para a propagação de 
ideias sobre o lugar "capazes de influenciar nas atitudes e identidades dos alunos", tanto de forma positiva quanto negativa (SANTOS, 2007, p. 8).

No nosso ponto de vista, tais limitações podem ser superadas a partir da ampliação dos conhecimentos sobre o lugar de vivência de forma mais sistematizada, através de estudos teóricos que contemplem/problematizem seus bairros, cidade, município nos seus vários aspectos. Mas também consideramos importante que o professor alie o domínio dos conteúdos específicos utilizados para ensinar o seu lugar com a vivência cultural, tal como conhecer os bairros, ir ao cinema, festas e eventos, entre outros. Contraditoriamente, Bento (2011) adverte que o professor sofre uma ausência de vida cultural como reflexo das más condições de trabalho vivida historicamente pelos profissionais de educação os quais além de sofrerem com a fala de reconhecimento profissional perante a sociedade brasileira, são mal remunerados, sendo assim um empecilho para que o mesmo invista em sua formação continuada. Essa falta de vida cultural, principalmente na cidade onde atua como professor é revelada:

[...] quando o professor não consegue estabelecer com seus alunos uma ligação para além da sala de aula. Isso acarreta uma falha na ampliação do universo cultural desses alunos, pois eles ficam restritos ao estímulo de estarem abertos a diferentes leituras da realidade, sendo uma função básica da docência (BENTO, 2011, p. 83).

Face ao exposto, observa-se que vivenciar a cidade também influencia o processo de mediação docente e pode contribuir com bons resultados durante o processo de ensino e aprendizagem, bem como é a responsável por contribuir na formação ou reafirmação da identidade local ao se trabalhar com a mesma. Dessa forma, ampliar os conhecimentos sistematizados, tanto historicamente como espacialmente, e vivenciar o lugar onde se vive/trabalha para melhor conhecê-lo, é de fundamental importância, pois:

\begin{abstract}
A hipótese é que as pessoas tendem a elaborar imagens condizentes com os lugares que frequentam e com as experiências que vivenciam. Assim sua experiência espacial está limitada a bairros considerados violentos, há uma tendência de que ela generalize essa imagem de cidade. Se apenas frequentou bairros nobres e adjacentes, tende a elaborar uma imagem distinta da primeira. Ou mesmo, se nunca saiu de seu bairro ou de sua cidade, acaba elaborando uma visão restrita sobre o espaço geográfico (SANTOS, 2007, p. 153).
\end{abstract}

Em síntese, entendemos que essas relações conflituosas existentes entre a falta de embasamento teórico-metodológico consistente e conhecimento sobre a realidade local, aliado à falta de vivência espacial e cultural dos docentes podem interferir na mediação pedagógica, tendo como consequência a propagação de ideias que não contribuem para a formação da identidade dos alunos com o lugar Feira de Santana.

\title{
Percurso Metodológico
}

Essa investigação engaja-se nos contornos da pesquisa qualitativa que, segundo Lüdke e André (1986, p. 18) trata-se de um estudo "[...] que se desenvolve numa situação natural, é rico em dados descritivos, tem um plano aberto e flexível e focaliza a realidade de forma complexa e contextualizada". E tem como uma de suas virtudes "[...] dar poder ou dar voz às pessoas, em vez de trata-las como objetos, cujo comportamento deve ser quantificado e estatisticamente modelado" (BAUER et al., 2002, p. 28). Somando-se a esses procedimentos supracitados adotamos na pesquisa os pressupostos de um estudo de caso, que para Yin (1989 apud BESSAN 2000, p. 1) consiste numa "[...] inquirição empírica que investiga um 
fenômeno contemporâneo dentro de um contexto da vida real, quando a fronteira entre o fenômeno e o contexto não é claramente evidente e onde múltiplas fontes de evidência são utilizadas".

A pesquisa tem como sujeitos professoras e alunos de um colégio público localizado num bairro periférico, na porção norte da cidade de Feira de Santana (BA). Trata-se de uma instituição que oferece ensino nos três turnos para alunos do ensino fundamental e médio. E que devido sua proximidade com a Universidade Estadual de Feira de Santana (UEFS), se tornou um colégio que recebe muitos estudantes universitários, seja para desenvolver estágios obrigatórios, não obrigatórios, bolsas de Iniciação científica ou de iniciação à docência. Também faz parte do campo de investigação do grupo de pesquisa intitulado "Lugar, formação docente e elaboração de material didático-pedagógico sobre Feira de Santana/BA", projeto maior ao qual este trabalho está vinculado.

Para atingir os objetivos propostos, a pesquisa foi dividida em três momentos. No primeiro momento realizamos um levantamento bibliográfico com base na problemática e nos principais conceitos abordados na pesquisa e teve como referência a consulta de livros, artigos, teses, dissertações, monografias, que pudessem contribuir para o desenvolvimento da temática estudada. Vale ressaltar, que o embasamento teórico também foi norteado pela participação nos estudos e reflexões realizadas pelo/no Grupo de Estudos Lugar, que discute o lugar e a cidade de Feira de Santana como conteúdo pedagógico.

O segundo momento consistiu na produção de dados primários através da realização de entrevistas semiestruturadas e aplicação de 35 questionários com perguntas abertas e de múltipla escolha. As respostas das questões abertas foram agrupadas de maneira que agregassem as que possuíam conteúdo semelhante e tiveram por finalidade identificar os discursos, imagens e as práticas pedagógicas dos professores ao abordarem Feira de Santana em sala de aula e de que forma esses discursos interferem na formação e/ou reafirmação da identidade dos alunos para com o lugar Feira de Santana. Aos alunos foram aplicados 32 questionários; destes, 16 destinaram-se ao ensino fundamental (oito alunos do $6^{\circ}$ ano e oito do $7^{\circ}$ ano) e 16 ao ensino médio (oito alunos do 1 ano e oito do $3^{\circ}$ ano).

Entre os oito alunos de cada ano que responderam aos questionários, três foram escolhidos aleatoriamente para a realização de entrevistas semiestruturadas, no sentido de aprofundar as respostas. A escolha das professoras ocorreu de forma abrangente com o objetivo de abarcar todos os professores de geografia que atuam no colégio. As 05 professoras foram aplicados tanto os questionários ${ }^{3}$ quanto entrevistas, pela necessidade de uma compreensão mais detalhada do objeto em estudo (GASKELL, 2003). Já análises do corpus textual das entrevistas pautaram-se nos princípios da análise de conteúdo (BARDIN, 1977).

A escolha das turmas para aplicação dos questionários e realização de entrevistas semiestruturadas ocorreu através dos seguintes critérios: uma turma do $6^{\circ}$ ano do ensino fundamental foi escolhida por ser comumente nesta série que se inicia o estudo do conceito de lugar, e consequentemente, é o momento de contribuir para a construção ou reafirmação da identidade dos alunos para com o seu Lugar. Já a escolha de uma turma do $7^{\circ}$ ano do ensino fundamental, teve como objetivo identificar o que os alunos trazem sobre o conceito de lugar e de identidade estudados no $6^{\circ}$ ano.

Quanto à escolha de uma turma do primeiro $1^{\circ}$ ano do ensino médio, teve por finalidade identificar o conceito de lugar e de identidade ao sair do ensino fundamental. Contudo, a escolha de uma turma do $3^{\circ}$ ano do ensino médio teve como objetivo identificar como, ao longo da escolaridade o conceito de lugar e identidade chega até este ano, em que os alunos estão prestes a completar o ensino médio.

Por fim, no terceiro momento realizamos a organização, tratamento, análise e interpretação dos dados, pontuando as semelhanças e diferenças entre as respostas fornecidas 
pelos alunos e professores a respeito da identidade e afetividade para com o lugar Feira de Santana, bem como identificou em que medida os discurso e práticas dos professores interferem na formação e/ou reafirmação da identidade para com este lugar.

\section{O Estudo do Lugar Feira de Santana nas aulas de geografia, segundo as professoras investigadas}

Para evitar a identificação das professoras investigadas seus nomes foram substituídos pelas siglas P1, P2, P3, P4 e P5, como pode ser observado no Quadro 1

Quadro 1- Idade, graduação, experiência em anos, carga horária e turmas que possuem

\begin{tabular}{|c|c|c|c|c|c|}
\hline Docente & Idade & $\begin{array}{c}\text { Licenciatura } \\
\text { em }\end{array}$ & $\begin{array}{c}\text { Experiência } \\
\text { em anos }\end{array}$ & $\begin{array}{l}\text { Carga } \\
\text { Horária }\end{array}$ & Turmas que Leciona \\
\hline P1 & 32 & Geografia & 6 & 40 & $1^{\circ} 2^{\circ}$ e $3^{\circ}$ ano do Ens. Médio. \\
\hline $\mathrm{P} 2$ & 35 & Geografia & 9 & 60 & $\begin{array}{c}6^{\circ} \text { ano do Ens. Fundamental e } 1^{\circ} \\
\text { e } 2^{\circ} \text { ano do Ens. Médio. }\end{array}$ \\
\hline P3 & 39 & $\begin{array}{l}\text { Estudos } \\
\text { Sociais }\end{array}$ & 10 & 60 & $\begin{array}{l}9^{\circ} \text { ano do Ens. Fundamental e } 1^{\circ} \\
\text { e } 2^{\circ} \text { ano do Ens. Médio e EJA. }\end{array}$ \\
\hline $\mathrm{P} 4$ & 45 & Geografia & 6 & 60 & $\begin{array}{l}6^{\circ} \text { do Ens. Fundamental e } 1^{\circ} \text { e } 2^{\circ} \\
\text { ano do Ens. Médio e no EJA. }\end{array}$ \\
\hline P5 & 53 & $\begin{array}{l}\text { Estudos } \\
\text { Sociais }\end{array}$ & 23 & 60 & $\begin{array}{c}6^{\circ} \text { e } 7^{\circ} \text { anos do Ens. Fundamental } \\
\text { e } 1^{\circ} \text { e } 2^{\circ} \text { do Ens. Médio. }\end{array}$ \\
\hline
\end{tabular}

Fonte: Pesquisa de campo realizada entre os meses de Julho a Agosto de 2014.

Ao analisar o Quadro 1 percebe-se que quatro das cinco professoras possuem carga horária de 60 horas, o que nos faz pressupor que o tempo que dispõem para elaborar os planos de aula e realizar pesquisas sobre a realidade local possa ser insuficiente. Haja vista que a cidade de Feira de Santana não é contemplada nos livros didáticos, acarreta tempo para pesquisar e sistematizar os conteúdos. Essa preocupação é pertinente, pois segundo Santos (2007) a falta de material didático que aborde o lugar implica em dificuldades em ensinar assuntos mais próximos ao cotidiano dos alunos, principalmente pela falta de conhecimento sistematizado e ausência de material didático temático sobre o lugar.

Essa falta de conhecimento sistematizado que os professores que atuam nas séries iniciais do Ensino Fundamental e Médio possuem sobre a escala local (cidade, bairro) é resultado, segundo Lima e Thomas (2007, p. 03), da não obrigatoriedade em estudar, durante a graduação, "[...] a Geografia do município onde atua e nem metodologias para isso, ou seja, se já fazem isso, foi por iniciativa do próprio professor na ânsia de poder ter mais subsídios para suas aulas". Daí a importância em se investir, tanto na formação inicial quanto continuada, para que se evite o a abordagem do lugar de vivência (escala local), apenas como exemplificação ou enumeração, sem que haja a problematização.

Com relação ao tempo de serviço observa-se que a maioria das professoras é experiente, com mais de 10 anos serviço e diante disto, pressupomos que as mesmas apresentam domínio de conteúdo específico, didático e experiência importantes para o processo de mediação pedagógica. Entretanto, a abordagem do lugar requer que professor também possua conhecimentos específicos, didáticos, experienciais, espacial e interpessoal com e no lugar de vivência, assim como o articule com demais escalas. Nessa perspectiva, 
para alcançar essa combinação é importante que o professor conheça aspectos históricos e vivencie a cidade de Feira de Santana, para que possa abordá-la em sala de aula, mostrando suas potencialidades, problemas e possíveis soluções.

Como já ressaltado anteriormente, morar em um lugar pressupõe o estabelecimento de laços identitários (ou não) com o mesmo. Diante disto, buscamos identificar se as professoras investigadas gostam e se identificam com Feira de Santana, pois pressupomos que ao gostar e se identificar com a cidade as mesmas poderão apresentar um maior cuidado em destacá-la em suas aulas, articulando este lugar aos conteúdos trabalhados, assim como contribuir de forma positiva para a formação e/ou reafirmação da identidade dos alunos para com o lugar Feira de Santana.

Suas respostas indicaram que sim, gostam desse lugar, porém três justificaram que esse gostar e essa identificação possuí relação direta com a presença de familiares que residem na cidade e pelo estabelecimento de laços de amizade com e na cidade, conforme expressam seguintes falas:

Porque cresci aqui tenho uma história de vida nesta cidade (P3); Gosto da cidade e das pessoas $(\mathrm{P} 1)$.

As demais responderam que gostam e se identificam com a cidade de Feira de Santana devido às oportunidades de trabalho, como pode ser observado nas justificativas a seguir:

É uma cidade que oferece muitas oportunidades de crescimento profissional (P4); Porque é a cidade onde trabalho (P2).

Entendemos que esse gostar pode ser potencializado ou desprezado, a depender da forma como as professoras se relacionam na e com a cidade de Feira de Santana. Pode ser potencializado à medida que as mesmas vivenciem a cidade, conhecendo-a e se reconhecendo enquanto sujeitos transformadores e pertencentes a esse lugar. Essa vivência, juntamente com a ampliação dos saberes (através de leituras de artigos, dissertações, teses, livros, jornais, revistas, filmes, documentários, telejornais, entre outros) pode possibilitar o entendimento do processo de formação, desenvolvimento e dinâmicas atuais de diversos lugares presentes na cidade e assim se desfazer de determinados preconceitos e generalizações oriundos do senso comum.

Outra preocupação da presente pesquisa foi identificar se as professoras investigadas abordam Feira de Santana nas aulas de Geografia. Como resposta, quatro delas responderam que sim, e apenas uma não aborda. Quando indagadas sobre a importância desse estudo, as professoras ressaltaram a importância dos alunos conhecerem e entenderem a realidade onde vivem, conforme indicam as justificativas a seguir:

Para que os estudantes entendam a realidade e o lugar onde vivem (P1); É importante que o aluno tenha conhecimento sobre sua cidade $(\mathrm{P} 4)$.

Ao abordar a cidade de Feira de Santana nas aulas é imprescindível que o professor conheça seus aspectos físicos, econômicos, históricos e sociais e, principalmente, tenha consciência de que a mesma pode se constituir como um importante recurso didático nas exemplificações e problematizações durante a mediação pedagógica. Partimos do entendimento de que "[...] ensinar e estudar geografia tendo a cidade como ponto de partida facilita e socializa o processo de aprendizagem, porque os alunos articulam os conceitos científicos em redes de significados que não lhes são estranhos" (CASTELLAR E VILHENA, 
2012, p. 123). Além disso, contribui na identificação dos alunos para com o seu lugar ao conhecer e compreender melhor os espaços vivenciados cotidianamente.

Entretanto, quando indagadas se entendiam Feira de Santana, como recuso didático nas aulas de geografia, apenas uma professora respondeu de forma positiva; as demais deixaram a questão em branco.

De acordo com Santos e Santos (2016) a produção e distribuição de recursos didáticos no Brasil pautam-se em políticas educacionais as quais muitas vezes pensam no geral em detrimento do especifico. Tais recursos didáticos, distribuídos gratuitamente na rede pública de ensino, muitas vezes não condizem com as necessidades de professores e alunos. Nesse contexto, encontra-se a cidade de Feira de Santana que, igualmente a muitas cidades brasileiras, não está entre os conteúdos presentes nos livros didáticos, tendo em vista que os lugares mais referenciados são aqueles de importância política e econômica nacional e ou internacional, não contemplando as especificidades. Isso exige dos professores, que pretendem ensinar de forma mais contextualizada, a elaboração de recursos didáticos e atividades condizentes com a realidade local dos discentes, para que possam ser utilizados na mediação pedagógica do conteúdo em estudo, seja para exemplificar e/ou problematizar aspectos presentes na cidade, no bairro ou na rua onde os estudantes moram.

A partir das ideias expressas anteriormente, indagamos às professoras investigadas se elas costumam elaborar atividades e/ou recursos didáticos sobre Feira de Santana para nortear o processo de mediação pedagógica, a exemplo de textos, maquetes, fotografias, mapas, vídeos, jornais, cartazes, entre outros. Dentre as cinco professoras consultadas, quatro afirmaram que elaboram recursos e atividades contemplando o assunto sobre Feira de Santana. Entre os materiais mais elaborados estão os textos e cartazes com três indicações; painéis, vídeos e mural temático com duas indicações; imagens e slides com uma indicação cada.

Por fim, tivemos a curiosidade em saber se as professoras apresentam dificuldades em relacionar os conteúdos presentes no livro didático ao espaço de vivência dos alunos e quais seriam essas dificuldades. Como resposta, duas professoras afirmaram não ter dificuldades, porém as demais sinalizaram que sim:

A principal dificuldade é localizar onde ocorre a temática em estudo na sala com um тара (P4);

Principalmente no ensino fundamental e médio, por que os conteúdos são voltados para Europa, Ásia, África, etc. (P3).

A primeira resposta indica que faltam mapas temáticos e físicos que trabalhem o recorte espacial Feira de Santana. Contudo, a dificuldade expressa na segunda resposta poderia ser reduzida caso maioria das professoras considerasse Feira de Santana como recurso didático. Ou seja, trouxesse exemplos utilizando a cidade para facilitar o entendimento dos alunos, partindo de uma realidade conhecida e muitas vezes experienciada pelos mesmos, visto que, com o processo de globalização muitas características do mundo são possíveis de serem encontradas na escala local. Afinal, como afirma Callai (2009), o lugar é um importante laboratório para se entender o mundo.

\section{O Estudo do Lugar Feira de Santana nas aulas de geografia, segundo os alunos investigados}

Como já explicitado na metodologia, foram aplicados questionários a 32 alunos, sendo uma amostragem de 08 alunos de cada ano ( $6^{\circ}$ ano, $7^{\circ}$ ano, $1^{\circ}$ ano e $3^{\circ}$ ano). Desses, foram selecionados 03 alunos de cada ano para a realização de entrevistas. Embora as respostas se 
aproximem, para identificar o ano ao qual pertencem, nomeamos A1 identificando o $6^{\circ}$ ano e A2 representando o $7^{\circ}$ ano, ambos do ensino fundamental; B1 para $01^{\circ}$ ano e B2 representando o $3^{\circ}$ ano, ambos do ensino médio. Entre os alunos do ensino fundamental, as idades variam entre 13 e 14 anos. Já os alunos do ensino médio apresentam idades entre 15 e 18 anos. Dos alunos investigados, 21 moram em Feira de Santana desde que nasceram.

Inicialmente indagamos aos alunos se eles gostavam de morar em Feira de Santana e por que. Os alunos do ensino fundamental afirmaram gostar de morar em Feira de Santana, justificando que este gostar possui relação com o fato de terem nascido na cidade e nela estabeleceram laços de amizade, de convivência, com expresso nas falas a seguir:

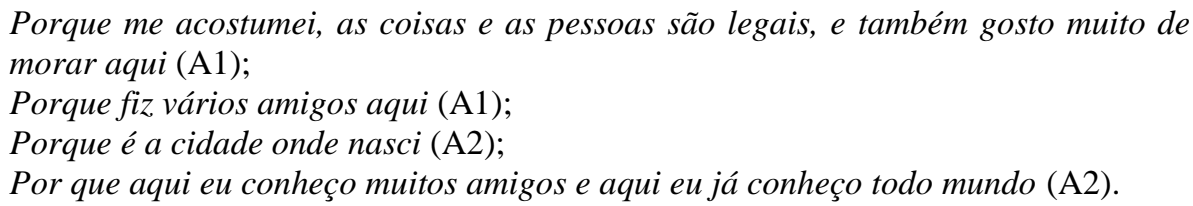

Já entre os alunos do ensino médio, dos 16 consultados apenas um afirmou não gostar da cidade, afirmando que não vejo nada de legal aqui (B1). Os demais afirmaram gostar de morar em Feira de Santana. O motivo que os fazem gostar desta cidade são os mesmos que os alunos do ensino fundamental, ou seja, os laços familiares e de amizade estabelecidos, porém destacaram outra questão importante condizente com a preocupação na idade deles, que são as oportunidades de emprego oferecidas na cidade. Esses pensamentos são revelados nas seguintes frases:

Porque gosto de morar perto de minha família (B1);
Porque já fiz amigos aqui, gosto de morar aqui (B2);
Porque tem muitos recursos profissionais (B1);
Porque tem muitas oportunidades de curso e empregos (B2).

A afetividade pelo lugar pode ser potencializada através da ampliação dos conhecimentos teóricos e empíricos sobre o mesmo. Isso posto, buscamos identificar junto aos alunos a maneira como as professoras abordam a cidade de Feira de Santana, no sentido de contrapor as respostas. Os alunos do ensino fundamental responderam que sim, e justificaram que as professoras abordam o processo histórico de formação da cidade e aspectos atuais de sua organização socioespacial. Entre os alunos do ensino médio, apenas três alunos responderam que os professores abordam esse assunto nas aulas de geografia, dando como exemplo as saídas de campo pela cidade e visitas ao centro industrial de Feira de Santana. Já os alunos que responderam negativamente deixaram a justificativa em branco.

Essas respostas abrem espaço para a próxima pergunta, onde indagamos aos sujeitos investigados se eles gostavam de estudar sobre a cidade na qual residem. Consideramos importante que o aluno goste de estudar aspectos de Feira de Santana para ampliar seus conhecimentos e compreensões sobre a cidade. Esse gostar pode ser potencializado ou renegado, a depender da mediação pedagógica do professor e da forma como ele se refere à cidade. Assim, todos os alunos do ensino fundamental responderam que gostam de estudar a cidade, principalmente para conhecer a história do lugar onde moram. Entre os investigados do ensino médio, 14 alunos disseram que sim e 02 disseram que não.

Conhecer e saber as potencialidades e problemas da cidade nos remete a indagar aos alunos se a abordagem do lugar Feira de Santana, para exemplificar o conteúdo abordado, facilita o seu entendimento. Os alunos do ensino fundamental todos responderam que sim. Já os alunos do ensino médio, 14 assinalaram afirmativamente. Esse resultado positivo nos faz 
pressupor que quando partimos de uma realidade conhecida e fazemos associações com outras realidades, além de despertar um maior interesse, amplia o campo de abstração dos alunos.

Levando-se em consideração os aspectos anteriormente apresentados, comparamos algumas respostas das professoras e dos alunos sobre os aspectos afetividade, ideias e identidades em relação ao lugar Feira de Santana, no sentido de identificar possíveis influencias da mediação docente nas falas dos alunos.

A ampla maioria dos professores e alunos investigados se identifica com o lugar Feira de Santana a partir de laços afetivos de amizade e família. Porém, as professoras e os alunos do ensino médio ampliam essa identidade para as relações de oportunidade de trabalho que a cidade oferece. Entendemos que esse fato pode estar associado à influência exercida pela visão de algumas das professoras que entendem a cidade de Feira de Santana como um lugar apenas para trabalho. $\mathrm{O}$ segundo fator está atrelado aos conteúdos lecionados no $1^{\circ}$ ano, pois nesta série se estuda processo de industrialização e uma das professoras respondeu que trabalha com o Centro Industrial Subaé, o que nos faz pressupor que a mesma ressalta as potencialidades trabalhistas neste setor. Por fim é no $3^{\circ}(\mathrm{B} 2)$ ano que acreditamos que a imagem de Feira de Santana, como um lugar para trabalho se acentua, visto que, trata-se de um ano em que os alunos estão prestes a findar o ensino médio e já pensam nas oportunidades de trabalho ao concluírem.

Por fim, ao analisar e comparar as respostas de professores e alunos, principalmente do ensino médio, observamos que ao abordarem Feira de Santana nas aulas de geografia as docentes não se preocupam com a formação de identidades e/ou afetividades em relação a este lugar. Valorizam, sobretudo, os aspectos físicos e, principalmente, econômicos, como ressaltado por três das cinco professoras investigadas. Diante do exposto pressupomos que no ensino médio há uma maior influência docente reforçando uma imagem de Feira de Santana como uma cidade de trabalho, imagem essa já tão divulgada pela mídia e pelo senso comum. Advertimos, entretanto, o cuidado que se deve ter para não contribuir para a propagação dessa imagem da cidade voltada apenas para o trabalho, e nesse sentido, é importante que o professor também destaque as opções de cultura e lazer que vem sendo oferecidas ao longo dos últimos anos.

\section{Consideracões Finais}

O estudo do lugar se faz necessário diante do atual processo de globalização, responsável por promover tendências que criam padrões de vidas que almejam homogeneização gostos, costumes, culturas, entre outros. Essas alterações são sentidas de forma mais contundentes no lugar de vivencia, pois a transformações ocorrem a uma velocidade e intensidade sem desmedida, que quando os indivíduos as percebem lhes causam estranheza e não se sentem pertencentes à realidade local.

Perante a esse contexto conflituoso, o estudo do lugar surge como uma possibilidade de se compreender o local a partir da articulação com o global, buscando identificar e analisar de que maneira acontecem esses rebatimentos. Porém, tal estudo exige que o professor de geografia possua conhecimentos teórico-metodológicos, assim como entenda o aluno enquanto sujeito ativo durante o processo de mediação pedagógica, para que possa dessa forma contribuir positivamente na formação e/ou reafirmação de identidades dos alunos para com seu lugar de vivencia. Face ao apresentado, esse artigo teve por objetivo apresentar os resultados de uma investigação que procurou identificar identidades, afetividades e práticas pedagógicas de professoras de geografia em relação à cidade de Feira de Santana, bem como a influência da sua mediação pedagógica na formação e/ou reafirmação de identidades e imagens dos alunos em relação a este lugar. 
Os dados indicam que os sujeitos investigados (alunos e professoras) gostam de morar na cidade de Feira de Santana e apresentam afetividade e identidades positivas em relação a este lugar, relações construídas pelos laços de família e amizade. Porém, as professoras e os alunos do ensino médio ampliam essa identidade para as relações de oportunidade de trabalho que a cidade oferece.

As professoras e alunos investigados consideram importante estudar e compreender o lugar onde moram e desenvolvem suas práticas espaciais cotidianas. Com relação à mediação pedagógica, as professoras utilizam a cidade de Feira de Santana para trazer exemplos que ajudam no entendimento do conteúdo pelo aluno, o que no nosso entendimento pode favorecer um melhor conhecimento sobre a sua cidade e de certa forma contribuir para a formação ou reafirmação da identidade dos alunos com o lugar Feira de Santana. No ensino médio, além de utilizada como exemplo na articulação entre o conteúdo e a realidade, Feira de Santana também é abordada como conteúdo específico a partir da solicitação de pesquisas sobre temas relacionados à indústria, transporte, comércio, população, problemas ambientais da referida cidade.

Para minimizar a falta de recursos didáticos específicos sobre o tema, as professoras costumam elaborar materiais didáticos sobre Feira de Santana em conjunto com seus alunos, sendo os principais elencados: vídeos, cartazes, imagens, seguidos de painéis, textos, slides e mural temático.

Com relação às imagens que se têm sobre Feira de Santana, os dados indicam a sua imagem atrelada a um lugar voltado para o trabalho, aparece justamente no ensino médio e dois fatores contribuem para esse pensamento. O primeiro está associado à influência, exercida pelo discurso de algumas das professoras que deixaram claro a sua relação e o entendimento dessa cidade como um lugar para o trabalho. $\mathrm{O}$ segundo fator está associado aos conteúdos lecionados no $1^{\circ}$ ano e $3^{\circ}$ anos, ambos atrelados a aspectos econômicos. Além disso, acreditamos que a imagem de Feira de Santana como um lugar para trabalho se acentua, visto que no ensino médio os alunos já estão pensando nas oportunidades de trabalho ao concluírem a educação básica.

Por fim, indagamos: será que essa abordagem realizada pelas professoras contribui, realmente, para reafirmação de identidades e afetividades de seus alunos em relação à Feira de Santana no sentido de pensar num vir a ser? A sua identidade se reduz a um lugar de trabalho? Ficam aqui essas perguntas.

\section{$\underline{\text { Notas }}$}

1 - O presente artigo faz parte de um Projeto de Iniciação Cientifica, intitulado: A influência docente na (re) construção do significado de lugar pelos alunos das escolas públicas de Feira de Santana-Ba. Financiado pela Fundação de Amparo à Pesquisa do Estado da Bahia-FAPESB.

2 - Ambas as perspectivas, de acordo com Straforini (2006), não atendem mais ao contexto atual, pois a linearidade foi rompida com o processo de globalização impulsionado pelo meio-técnico-cientificoinformacional, principalmente através dos meios de comunicação de massa, como a televisão que adentra ferozmente as residências faz com que o espaço imediato das pessoas não sejam mais apenas o manipulado o tocado e observado pela criança. A constante e maciça exposição das mercadorias e dos eventos pela mídia transforma-os em coisas concretas e possíveis de serem consumidas e vividas. Ver mais em: STRAFORINI, Rafael. Ensinar geografia: o desafio da totalidade-mundo nas séries iniciais. 2. ed. São Paulo: Annablume, 2006. 190 p.

3 - O questionário continha nove questões, dentre as quais apenas três eram de múltipla escolha; as demais eram para marcar sim ou não e justificar o porquê da escolha. 


\section{Referências}

BARDIN, Laurence. Análise de Conteúdo. Lisboa, Lisboa: Edições 70, 1977.

BAUER, Martin W et al. Qualidade, Quantidade e interesse do conhecimento-Evitando confusões. In: BAUER, Martin W; GASKELL, George (Org.). Pesquisa qualitativa com texto, imagem e som: um manual prático. 2. ed. Tradução de Pedrinho Arcides Guareschi. Petrópolis. RJ: Vozes, 2002. Cap. 1, pp 17-36.

BENTO, Izabella Peracini. Estudar a cidade e seus sujeitos para aprender geografia. In: MORAIS, Eliana Marta Barbosa; CAVALCANTI, Lana de Souza (Org.). Acidade e seus Sujeitos. 1. ed. Goiânia: Editora Vieira, 2011.

BRESSAN, Flávio. O método do estudo de caso. Fundação Escola de Comércio Álvares Penteado. São Paulo, v. 1, n. 1, jan/fev/mar. 2000.

CALLAI, Copetti Helena. Aprendendo a ler o mundo: a geografia nos anos iniciais do ensino fundamental. CADERNOS CEDES, Campinas, v. 25, n. 66, p. 227-247, maio/ago. 2005.

CALLAI, Copetti Helena. Estudar o Lugar para compreender o mundo. In: CASTROGIOVANNI, Antonio Carlos (Org.). Ensino de geografia: práticas e contextualizações no cotidiano. 7. ed. Porto Alegre: Mediação, 2009. Cap. 2, pp 83-134.

CARLOS, Ana Fani. O lugar no/do mundo. 1. ed. São Paulo: Labur Edições, 2007.

CASTELlAR, Sônia; VILHENA, Jerusa. Ensino de Geografia. São Paulo: Cengage Learning, 2012.

CAVALCANTI, Lana de Souza. Geografia, escola e construção de conhecimentos. 2. ed. Campinas, SP: Papirus, 2000.

GASKELL, George. Entrevistas individuais e grupais. In: BAUER, Martin W; GASKELL, George (Org.). Pesquisa qualitativa com texto, imagem e som: um manual prático. 2. ed. Tradução de Pedrinho Arcides Guareschi. Petrópolis. RJ: Vozes, 2002. Pat, pp $64-89$.

LIMA, Janete Aparecida de.; THOMAZ, Sergio Luiz. O estudo do lugar e a formação do aluno cidadão. $2007 . \quad$ UEM, Disponível em: $<$ http://www.gestaoescolar.diaadia.pr.gov.br/modules/conteudo/conteudo.php?conteudo=129 $>$. Acesso em: 05 de jun. 2016.

LUDKE, Menga.; ANDRÉ, Marli E. D. A. Pesquisa em educação: abordagens qualitativas. São Paulo: EPU, 1986.

MASETTO, Marcos Tarciso. Mediação pedagógica e o uso da tecnologia. In: . Moran, J Manuel; Masetto, Marcos T; Berhrens, M Aparecida (Org.). Novas tecnologias e mediação pedagógica. 13. ed. Campinas: Papirus, 2007. Cap. 3, pp 133-179. 
SANTOS, Célia Regina Batista dos. Desenvolvimento profissional de professores de Geografia: contribuições de um grupo de estudos sobre o ensino da localidade. São Carlos, 2007. Tese (doutorado em Educação) - CECH, UFSCar.

SANTOS, Edson da Silva.; SANTOS, Célia Regina Batista dos. Diagnóstico das temáticas sugeridas pelos professores de geografia e história da educação básica para elaboração de materiais didático-pedagógicos sobre Feira de Santana. Feira de Santana, 2016 (Relatório Técnico) - PPPG IC, UEFS.

STRAFORINI, Rafael. Ensinar geografia: o desafio da totalidade-mundo nas séries iniciais. 2. ed. São Paulo: Annablume, 2006 